\title{
Editorial
}

\section{The notion of relationship in branding}

Journal of Brand Management (2009) 17, 95-96. doi:10.1057/bm.2009.23

The notion of 'relationship' has been well established in marketing literature. Different facets of 'relationship' in the B-2-B sector, services, promotion and distribution have been written by scholars and practitioners. The issue of 'relationship' is gaining importance in the branding area as consumers construct an image of themselves in relation to the brands that they use on a daily basis. The four papers in this issue reflect the importance of 'relationship' in branding research.

Sung and Campbell use the investment model in explaining an individual's longterm orientation towards a 'relationship'. The issues of satisfaction, alternatives and investments have been discussed as key components of a 'relationship'. Using two studies, they found that the investment model is a good tool in explaining consumers' commitment to and 'relationship' with brands. They emphasize that managers ought to create an impression in the consumer's mind of a long-term 'relationship' with a brand.

The second paper, by Guthrie and Kim, highlights the importance of understanding the notion of 'relationship' between consumer involvement and brand perception. Using Kapferer and Laurent's Consumer Involvement Profile scale, they found an active 'relationship' between brand personality and brand attitude. The authors used three cosmetics brands, and 225 female students participated in the study. This paper discusses many interesting findings to which managers should pay attention.

The issue of 'relationship' between brand equity and product-related attributes is discussed in the third paper, by Fetscherin and Toncar. They present these two constructs within the German automobile market. The authors develop four hypotheses around product attribute, price, brand equity, market share and product variety. They emphasize that this study uses actual price for evaluating brand equity rather than perceived price or perceived value. The generalized model developed can be used to identify which product attributes, as well as other variables, contribute the most and the least to the price. To the managers, the authors emphasize that the model can be used to approximate the price of existing and new automobiles.

The last paper, by Carroll, posits that branding strategy becomes less about market share and more about emotional 'relationship'. Consumers use brands less as bundle of benefits and more as ideas that create social meaning and that have the power to generate community acceptance. Carroll uses Miu-Miu and Maggie Gyllenhaal, and Versace and Madonna as part of their analysis within fashion categories using celebrities as endorsers. The author concludes the paper by emphasizing the importance of visual images and cues as a form of aesthetic expression. 
I feel that the four papers above have captured the essence of 'relationship' in branding, vis-a-vis that consumers relate to brands at many different levels. We at $J B M$ try our best to provide you with papers that are leading-edge, thoughtful and scientifically rigorous. I hope you enjoy reading this and future issues of $J B M$.

T.C. Melewar Joint Editor-in-Chief 